\title{
A study of the effect of $X$-ray irradiation on the structure of Narafilcon A biopolymer soft contact lenses
}

\author{
Katarzyna Filipecka, ${ }^{1, A-D}$, Mariusz Budaj ${ }^{2, A-D}$, Bogdan Miśkowiak ${ }^{2, E, F}$, Sylwia Mandecka ${ }^{3, B, C}$, Radosław Mandecki ${ }^{3, B, C}$, \\ Małgorzata Makowska-Janusik ${ }^{1, E, F}$, Jacek Filipecki ${ }^{1, E, F}$ \\ ${ }^{1}$ Institute of Physics, Faculty of Mathematics and Natural Sciences, Jan Dlugosz University in Czestochowa, Poland \\ ${ }^{2}$ Department of Optometry and Biology of Visual System, Poznan University of Medical Sciences, Poland \\ ${ }^{3}$ Department of Radiotherapy, Specialist District Hospital, Częstochowa, Poland \\ A - research concept and design; $\mathrm{B}$ - collection and/or assembly of data; $\mathrm{C}$ - data analysis and interpretation; \\ $D$ - writing the article; $E$ - critical revision of the article; $F$ - final approval of the article
}

Address for correspondence

Jacek Filipecki

E-mail: j.flipecki@ajd.czest.pl

Funding sources

None declared

Conflict of interest

None declared

Received on June 1, 2018

Reviewed on July 24, 2018

Accepted on September 25, 2018

Cite as

Filipecka K, Budaj M, Miśkowiak B, et al. A study of the effect

of $\mathrm{X}$-ray irradiation on the structure of Narafilcon A biopolymer soft contact lenses. Polim Med. 2018;48(1):11-16.

doi:10.17219/pim/96288

DOI

10.17219/pim/96288

Copyright

( 2018 by Wroclaw Medical University

This is an article distributed under the terms of the

Creative Commons Attribution Non-Commercial License

(http://creativecommons.org/licenses/by-nc-nd/4.0/)

\section{Abstract}

Background. The effects of external factors such as X-ray irradiation on the structure and physical properties of contact lenses are very important for both the patients using contact lenses and medical personnel.

Objectives. The aim of the study was to investigate the effect of X-rays on the structure of Narafilcon A silicone-hydrogel contact lenses.

Material and methods. In order to study the structural changes caused by X-rays in Narafilcon A polymer contact lenses, the following spectroscopy methods were used: positron annihilation lifetime spectroscopy (PALS), Fourier transform middle infrared spectroscopy (FTIR) and Raman spectroscopy (RS). Irradiation of the investigated sample was carried out using an Elekta Synergy accelerator. The contact lenses were irradiated with the following total doses of X-rays: $0.05 \mathrm{~Gy}, 0.5 \mathrm{~Gy}, 0.8 \mathrm{~Gy}$, and $1.0 \mathrm{~Gy}$.

Results. The PALS measurements showed that $X$-ray irradiation caused slight changes in the size of the free volume and the fractional free volume in the structure of the polymer contact lenses examined. However, the FTIR and RS measurements showed that X-rays did not break the monomer bonds in the polymeric structure of the sample.

Conclusions. The changes revealed by the PALS method may be related to possible displacement of monomer chains, resulting in changes in the dimensions and numbers of free volumes. The finding that $X$-ray radiation does not affect or damage polymer bonds can in the future contribute to the use of $X$-ray and gamma radiation to sterilize contact lenses.

Key words: positron annihilation lifetime spectroscopy, Fourier transform middle infrared spectroscopy, Raman spectroscopy, contact lens, radiation 


\section{Introduction}

Structural studies on amorphous polymer materials used in medicine, e.g., for the production of contact lenses, have developed rapidly in recent years. ${ }^{1,2}$ The effects of external factors such as X-ray radiation on the structure and physical properties of contact lenses are very important for patients using contact lenses and for medical personnel, since they are exposed to X-ray radiation at work and/or during medical tests. The objective of this study was to examine changes in the polymer structure of Narafilcon A soft silicone-hydrogel contact lenses (a very popular type of contact lens) due to exposure to X-ray irradiation. Positron annihilation lifetime spectroscopy (PALS), supplemented by Fourier transform middle infrared spectroscopy (FTIR) and Raman spectroscopy (RS) were used to investigate the structure of Narafilcon A contact lenses before and after irradiation.

Narafilcon A contact lenses are daily disposable lenses made of a super-breathable silicone-hydrogel material that maximizes the availability of oxygen to the wearer's open eye. ${ }^{3}$ The structural formula of the silicone-hydrogel material is presented in Fig. 1.

Positron annihilation is a useful technology to investigate the characteristics of a material. Positrons injected into substances lose their energy through elastic collisions with electrons and finally annihilate. In the case of a nonconductive molecular material, in addition to the annihilation of the positron, the formation and annihilation of positronium (Ps) take place. Positronium is the bound state of the positron and the electron, with an atomic radius comparable to that of a hydrogen atom. It exists in 2 spin states. One is called para-positronium ( $p$-Ps), in which the positron and electron spins are anti-parallel. The other state, ortho-positronium (o-Ps), corresponds to parallel particle spins. ${ }^{4,5}$ This process, which is referred to as "pick-off" annihilation, reduces the lifetime of $o$-Ps in polymer materials to a few nanoseconds. Ortho-positronium is localized in the space between and along polymer chains and at chain ends (free volume holes), and its lifetime indicates the mean radius of these holes. ${ }^{5,6}$<smiles>C=C(C)C(=O)OCCOCCOCCOCCOC(=O)C(=C)C</smiles><smiles>C=C(C)C(=O)OCC(O)COCCC[Si](C)(C)O[Si](C)(C)O[Si](C)(C)C(C)(C)C</smiles><smiles>C=CC(=O)N(C)CCCCC</smiles>

Fig. 1. The structural formula of the silicone-hydrogel material (Narafilcon A)
In our earlier papers, ${ }^{7-9}$ as well as in this paper, the relationship between the $o$-Ps lifetime and the size of free volume holes is described by the Tao-Eldrup model. ${ }^{5,10}$ Theoretical deliberations on the model show that lifetime (responsible for positronium formation) is expressed as a function of the radius $\tau_{3}$ of the free volume $R$, and is described by the following formula ${ }^{11,12}$ :

$$
\tau_{3}=0.5\left[1-\frac{R_{0}-\Delta R}{R}+\frac{1}{2 \pi} \sin \left(2 \pi \frac{R_{0}-\Delta R}{R}\right)\right]^{-1}
$$

where:

$\tau_{3}$ - lifetime values of $o$-Ps [ns];

$R_{0}=R+\Delta R[\mathrm{~nm}]$

$\Delta R=0.166 \mathrm{~nm}$ - the fitted empirical electron layer thickness; $R$ - the radius of free volumes [nm].

By fitting Equation (1) with measured values of $\tau_{3}$, the size of the free volume holes $V_{f}$ is a function of $R$, and is given by the following equation:

$$
V_{f}=\frac{4}{3} \pi R^{3} \quad\left[10^{-30} \mathrm{~m}^{3}\right]
$$

where:

$V_{f}$ - the free volume calculated from $\tau_{3}$ by using Equation (1) with a spherical approximation $\left[10^{-30} \mathrm{~m}^{3}\right]$;

$R$ - the radius of free volumes [nm].

The relative intensity of the longest component $I_{3}$ is usually connected with the density of a hole. To determine the fractional free volume $\left(f_{v}\right)$ in polymers, one can use a semi-empirical relation:

$$
f_{V}=C V_{f} I_{3} \quad[\text { a.u. }]
$$

where:

$V_{f}$ - the free volume calculated from $\tau_{3}$ by using Equation (1) with a spherical approximation $\left[10^{-30} \mathrm{~m}^{3}\right]$;

$I_{3}$ - the intensity of the long-lived component [\%];

$C$ - empirically determined to be 0.0018 of the specific volume data. ${ }^{13}$

In this study, the results of PALS indicated how X-ray irradiation affected the free volumes and the fractional free volumes in Narafilcon A contact lenses.

Investigations using FTIR and RS were also carried out in order to verify whether X-ray irradiation changed the structure of the bonds in Narafilcon A. The FTIR method makes use of the phenomenon of radiation absorption by the molecules of an investigated material within the infrared range, which enables obtaining spectra with absorption bands characteristic of the corresponding bonds. The RS method is based on the phenomenon of non-flexible scattering of monochromatic laser radiation, through which spectra containing bands characteristic of the corresponding bonds are obtained. Both methods are useful for investigating molecular bonds. The FTIR method makes it possible to indicate the polarity of intermolecular bonds, whereas the RS method reveals their covalent character. The 2 methods are complementary. ${ }^{14-16}$ 


\section{Materials and methods}

The study was carried out on originally packed Narafilcon A soft contact lenses, which belong to the siliconehydrogel family. Detailed parameters obtained from the manufacturer (Cooper Vision, Phoenix, USA) of the contact lenses are shown in Table 1.

Table 1. Detailed parameters obtained from the manufacturer of the contact lenses

\begin{tabular}{|c|c|c|c|}
\hline \multicolumn{1}{|c|}{ Sample } & Material & $\begin{array}{c}\text { Water } \\
\text { content } \\
{[\%]}\end{array}$ & $\begin{array}{c}\text { Oxygen } \\
\text { permeability: Dk } \\
\left(\times 10^{-11}\right)\end{array}$ \\
\hline $\begin{array}{l}\text { Soft contact lens } \\
\text { (silicone-hydrogel) }\end{array}$ & Narafilcon A & 46 & $100^{*}$ \\
\hline
\end{tabular}

* taking into account the edge effect and the border effect.

Irradiation of the samples was carried out using an Elekta Synergy accelerator MLCi 80 (Elekta Instrument AB, Stockholm, Sweden). ${ }^{17}$ The Elekta Synergy accelerator emits photon and electron radiation of nominal energy (photons - 4, 6, $15 \mathrm{MeV}$ and electrons - 6, 9, 12, $15 \mathrm{MeV}$ ) with a multi-leaf collimator (MLCi 80). The maximum dimension of the field adjusted by the jaws and MLCi is $40 \mathrm{~cm} \times 40 \mathrm{~cm}$. The samples were irradiated in a water phantom in reference conditions (field size: $10 \mathrm{~cm} \times 10 \mathrm{~cm}$; source to surface distance (SSD): $90 \mathrm{~cm}$; depth: $10 \mathrm{~cm}$; energy: $6 \mathrm{MeV}$ ). The apparatus was calibrated to 1 -to-1 relations, i.e., 1 monitor unit was equivalent to a dose of $1 \mathrm{~Gy}$. The contact lenses were irradiated with the following total doses of X-rays: 0.05 Gy, 0.5 Gy, 0.8 Gy, and 1.0 Gy, which are equivalent to doses that patients wearing contact lenses may be exposed to during medical X-ray examinations, or the medical personnel during their professional work with X-ray radiation. Irradiation of the samples in a water phantom was dictated by the fact that devices for measuring doses are calibrated in water. Moreover, doses given in water are more uniform and the electron equilibrium is maintained, which makes it easier to define the dose. As a result, we can precisely calculate the dose absorbed by contact lenses. According to the International Atomic Energy Agency (IAEA) TRS398 dosimetric standards, measurements should be performed in water. The previous IAEA dosimetric report (TRS277) allowed measurements in the air, but such measurements are extremely complex and it is difficult to define the dose. ${ }^{18}$

The PALS measurements were performed at room temperature using an ORTEC spectrometer (ORTEC, Oak Ridge, USA), based on a "start-stop" method. ${ }^{19,20}$ A spectrometer with a lifetime resolution - the full width at half maximum (FWHM) of 250 ps, monitored with a Cobalt-60 $\left({ }^{60} \mathrm{Co}\right)$ source, was used to record all the PALS spectra. Each sample consisted of 6 layers of contact lenses with a diameter of $10 \mathrm{~mm}$ and a thickness of $1 \mathrm{~mm}$. All the samples were of the same diameter and thickness. A sample, along with the source of positrons, which was the ${ }^{22} \mathrm{Na}$ isotope of an $4 \times 10^{5} \mathrm{~Bq}$ activity, formed the so-called "sandwich system".
The FTIR studies were carried out on a DigiLab Excalibur series spectrometer (Digilab Inc., Hopkinton, USA) equipped with a Pike MIRacle ${ }^{\mathrm{TM}}$ attenuated total reflection (ATR) attachment (PIKE Technologies Inc., Madison, USA). ${ }^{21}$ A total of 128 scans were accumulated in the range of $550-4000 \mathrm{~cm}^{-1}$ and the resolution was set at $4 \mathrm{~cm}^{-1}$.

The RS spectra were recorded using an alpha300 confocal Raman microscope (WITec Wissenschaftliche Instrumente und Technologie GmbH, Ulm, Germany) equipped with an air-cooled solid state laser, operating at $488 \mathrm{~nm}$, and a charge-coupled device (CCD) detector, cooled to $-82^{\circ} \mathrm{C}$. A dry Olympus MPLAN (1006/0.90NA) objective lens (Olympus Corp., Tokyo, Japan) was used. The power of the laser at the sample position was between 14.4 $\mathrm{mW}$ and $14.6 \mathrm{~mW}$ for each measurement. A minimum of 120 scans with integration times of $0.3-0.5 \mathrm{~s}$ and a resolution of $3 \mathrm{~cm}^{-1}$ were collected and averaged. ${ }^{21}$

\section{Results and discussion}

Positron lifetime spectra were analyzed using LT software (LT Software Solutions, Portsmouth, USA). ${ }^{22}$ The obtained positron lifetime values revealed the existence of 3 components $-\tau_{1}, \tau_{2}$ and $\tau_{3}$ in the positron lifetime spectrum. The component $\tau_{1}$ represents the annihilation of $p$-Ps, which in this paper fits a value of $0.125 \mathrm{~ns}$, while the component $\tau_{2}$ is typical for positron trapping. ${ }^{23,24}$ As in our previous papers on the subject, attention was paid to the analysis of the longest-lived component of the positron lifetime $-\tau_{3}$ (the "pick-off" process). ${ }^{7-9}$ The positron lifetime values of $\tau_{3} o$-Ps and their intensity $I_{3}$, hole radius $R$, the sizes of the free volumes $V_{f}$ and the fractional free volumes $f_{v}$ for all the samples before and after irradiation are given in Table 2 . The main parameters of annihilation converted to means \pm measurement error were calculated using LT software.

The relationship between the sizes of the free volumes $V_{f}$ and the fractional free volumes $f_{v}$ as a function of X-ray irradiation is shown in Fig. 2.

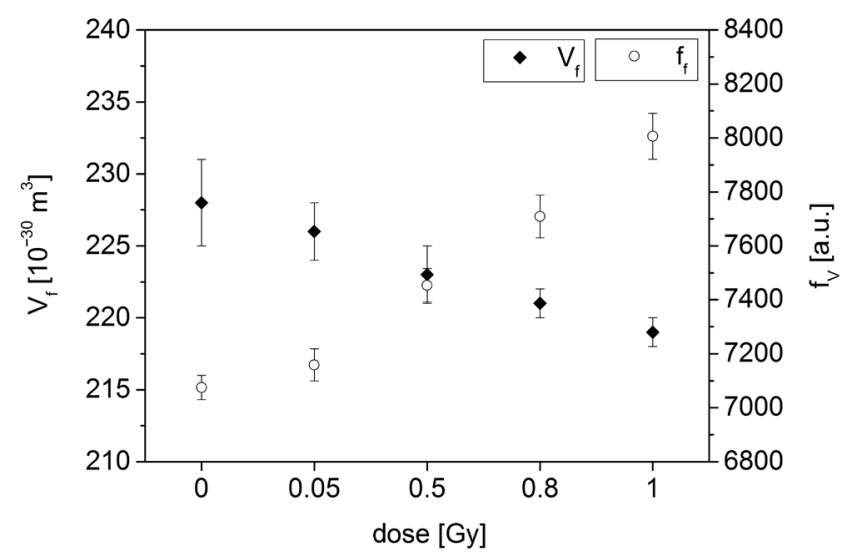

Fig. 2. The relationship between the sizes of the free volumes $V_{f}$ and the fractional free volumes $f_{v}$ as a function of $X$-ray irradiation 
Table 2. Calculated mean values of positron lifetime $\tau_{3}$ and their intensity $l_{3}$, hole radius $R$, the size of the free volume $V_{f}$, and the fractional volume $f_{v}$

\begin{tabular}{|c|c|c|c|c|c|}
\hline Sample & $\tau_{3}[\mathrm{~ns}]$ & $I_{3}[\%]$ & $R[\mathrm{~nm}]$ & $V_{f}\left[10^{-30} \mathrm{~m}^{3}\right]$ & $f_{v}[\mathrm{au}]$ \\
\hline Nar A & $3.167 \pm 0.052$ & $17.24 \pm 0.28$ & $0.379 \pm 0.002$ & $228 \pm 3$ & $7075 \pm 26$ \\
\hline Nar A - 0.05 Gy & $3.147 \pm 0.048$ & $17.60 \pm 0.31$ & $0.378 \pm 0.002$ & $226 \pm 2$ & $7159 \pm 28$ \\
\hline Nar A - 0.5 Gy & $3.133 \pm 0.042$ & $18.57 \pm 0.33$ & $0.376 \pm 0.001$ & $223 \pm 2$ & $7454 \pm 29$ \\
\hline $\operatorname{Nar} A-0.8 \mathrm{~Gy}$ & $3.121 \pm 0.036$ & $19.38 \pm 0.35$ & $3.375 \pm 0.001$ & $221 \pm 1$ & $7709 \pm 29$ \\
\hline Nar A - 1 Gy & $3.098 \pm 0.032$ & $20.31 \pm 0.37$ & $0.374 \pm 0.001$ & $219 \pm 1$ & $8006 \pm 31$ \\
\hline
\end{tabular}

Nar A - Narafilcon A; data presented as mean \pm standard deviation (SD).

It is evident from the results presented in Table 2 and Fig. 2 that as the dose of X-ray irradiation of the sample increases, there is a tendency towards decreases in the sizes of the free volumes $V_{f}$. However, there is a significant increase in the intensity $I_{3}$ of the $o$-Ps lifetime component and in the fractional free volumes $f_{v}$. It can be concluded that X-ray radiation doses from 0.05 Gy to 1 Gy result simultaneously in a slight decrease in the free volume dimensions and an increase in the number of free volumes in the irradiated sample.

In order to check whether the doses of X-ray irradiation affect the bond structure of the samples, measurements were made using RS and FTIR. The results are shown in Fig. 3-5. A close analysis of the obtained spectra indicated that irradiation of the samples did not cause any changes in their structure. Therefore, it is possible to conclude that in spite of active irradiation, no bonds disappeared nor did any additional bonds appear.

The study found no other significant changes in the structure of the samples examined or in the angles of the existing bonds. To sum up, the FTIR and RS studies showed that the applied radiation did not result in any significant changes in the structure of Narafilcon A lenses, or that the changes were so small that they could not be noticed in the corresponding spectra.

Ionizing radiation of different types, e.g., electron or gamma beams, has long been recognized as a suitable tool

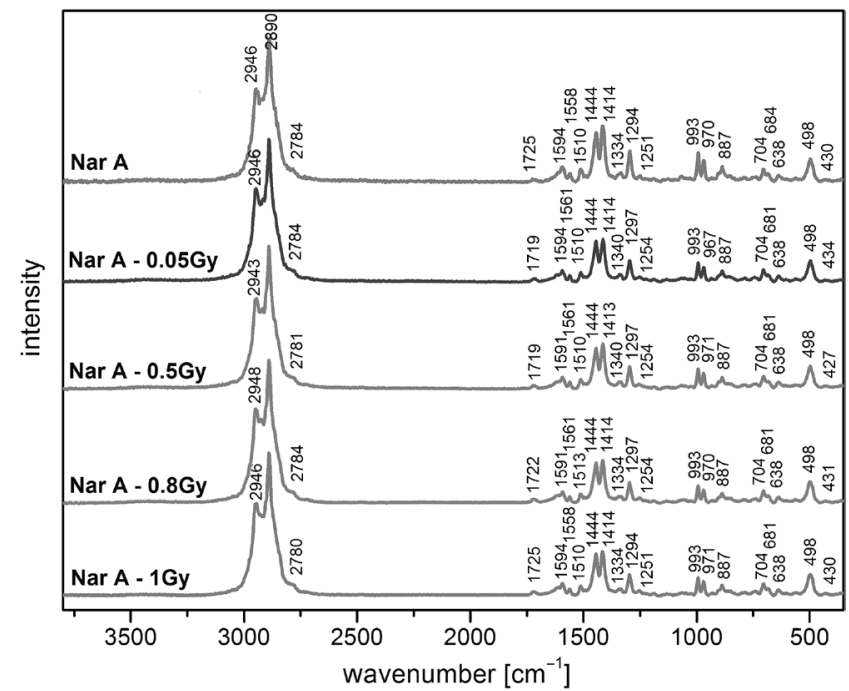

Fig. 3. Raman (RS) spectra of Narafilcon A contact lenses before and after $\mathrm{X}$-ray radiation

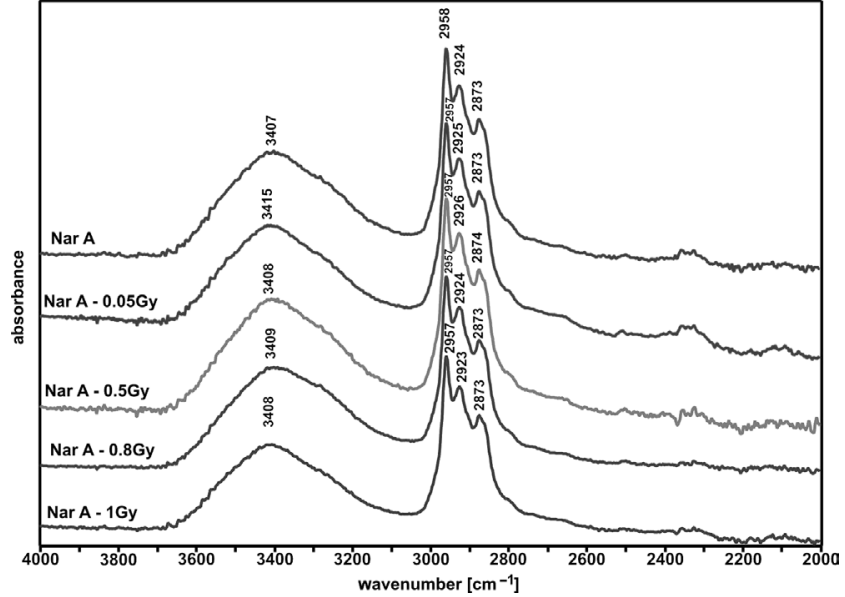

Fig. 4. Fourier transform middle infrared (FTIR) spectra of Narafilcon $A$ contact lenses before and after $X$-ray radiation (in the $2000-4000 \mathrm{~cm}^{-1}$ range)

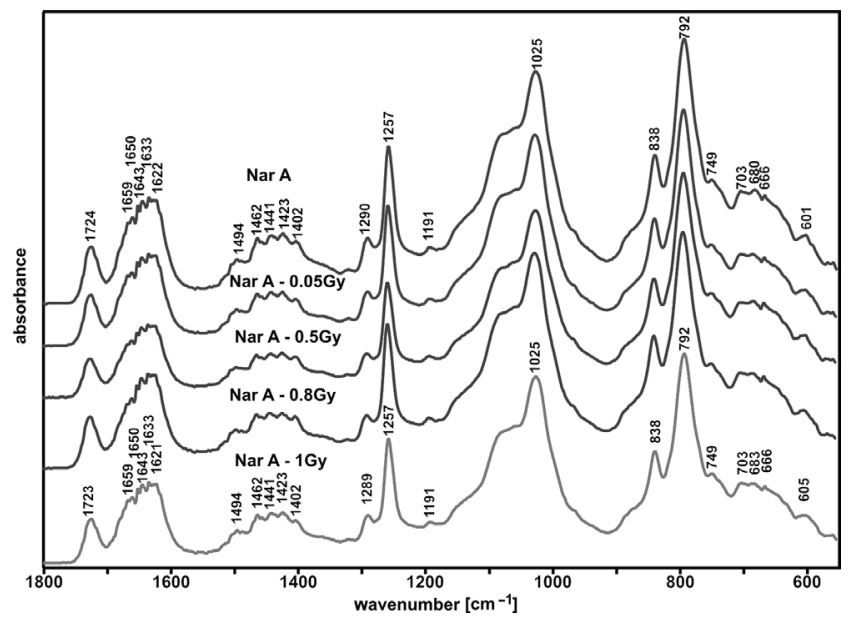

Fig. 5. Fourier transform middle infrared (FTIR) spectra of Narafilcon $A$ contact lenses before and after $X$-ray radiation (in the $550-1800 \mathrm{~cm}^{-1}$ range)

for the synthesis and modification of the structure and properties of polymeric materials. The exposure of polymers to ionizing radiation causes modifications such as radiation cross-linking, radiation-induced polymerization (graft polymerization and curing) and degradation of polymers. ${ }^{25}$ However, it should be pointed out that the effects of ionizing radiation on the properties and performance of polymers depend greatly on the chemical structure of a polymer.

One of the components of contact lenses is water. There are 3 main types of water found in polymers: non-freezable bound water (tightly bound), freezable bound water 
(loosely bound) and free water (bulk). Tightly bound water is generally attributed to water molecules directly linked by hydrogen bonding with the polar groups of the polymer matrix or strongly interacting with the ionic residues of the polymer matrix. Loosely bound water is usually related to water molecules loosely associated with the polar groups through hydrogen bonding in water-swollen polymers. ${ }^{26-28}$ Free (bulk) water refers to water molecules that do not interact with the polymer matrix, having hydrogen bonding typical of pure water. The amount of bound water can vary according to the polymer microstructure. Changes in the polymer structure caused by ionizing radiation can affect the water dynamics within the material. ${ }^{26}$

The dose of radiation necessary to produce similar significant effects in 2 different materials can vary significantly between them. From the results of this study, it can be deduced that X-ray irradiation causes only microstructural changes to the polymer network of Narafilcon A contact lenses.

\section{Conclusions}

The aim of this project was to study the effect of external X-ray radiation in total doses of $0.05 \mathrm{~Gy}, 0.5 \mathrm{~Gy}, 0.8 \mathrm{~Gy}$, and 1.0 Gy on changes in the soft structure of Narafilcon A contact lenses. The PALS method, which is extremely sensitive to detecting changes in the structure of materials, showed minor changes in the dimensions and number of free volumes in the lenses. At the same time, the FTIR and RS studies indicated that the applied radiation did not result in any significant changes in the bond structure of the examined material, or that the changes were so insignificant that they were impossible to trace in the corresponding spectra. We can speculate that the applied X-ray radiation was very hard and did not break the bonds, nor did it result in changing the bond angles of the monomers in the molecular structure of the Narafilcon A contact lenses. The changes revealed by the PALS method can be related to possible displacement of monomer chains, which results in changes in the dimensions and numbers of the occurring free volumes. The finding that $\mathrm{X}$-ray radiation does not affect or damage polymer bonds can in the future contribute to the use of X-ray and gamma radiation to sterilize contact lenses. This may become clearer as a result of further studies on the effect of electron-type radiation (beta radiation) on Narafilcon A samples, with the same total doses of irradiation as in this study, which will be carried out by the authors of this paper in the near future.

\section{References}

1. Tranoudis I, Efron N. In-eye performance of soft contact lenses made from different materials. Cont Lens Anterior Eye. 2004;27(3):133-148.

2. Wolffsohn JS, Hunt OA, Basra AK. Simplified recording of soft contact lens fit. Cont Lens Anterior Eye. 2009;32(1):37-42.
3. Morgan PB, Chamberlain P, Moody K, Maldonado-Codina C. Ocular physiology and comfort in neophyte subjects fitted with daily disposable silicone hydrogel contact lenses. Cont Lens Anterior Eye. 2013;36(3):118-125.

4. Jean YC. Characterizing free volumes and holes in polymers by positron annihilation spectroscopy. In: Advances with Positron Spectroscopy of Solids and Surfaces. NATO Advanced Research Workshop. 1993:563-580.

5. Eldrup M, Lighbody D, Sherwood JN. The temperature dependence of positron lifetimes in solid pivalic acid. Chem Phys. 1981;63:51-62.

6. Brandt W, Berko S, Walker WW. Positronium decay in molecular substances. Phys Rev. 1960;120(4):1289-1295.

7. Kocela A, Filipecki J, Korzekwa P, Golis E. Investigation of the free volume changes in one day hydrogel and one day silicone hydrogel contact lenses by means of positron annihilation lifetime spectroscopy. Polim Med. 2012;42(1):61-68.

8. Filipecki J, Kocela A, Korzekwa W. Study of free volumes of polymer hydrogel and silicone-hydrogel contact lenses by means of the positron annihilation lifetime spectroscopy method. Polim Med. 2014;44(4):255-260.

9. Filipecka K, Budaj M, Miśkowiak B, Makowska-Janusik M, Filipecki J. Comparison of occurrence of free volumes for rigid gas permeable and soft contact lenses. Polim Med. 2015;45(1):31-35.

10. Tao SJ. Positronium annihilation in molecular substances. $J$ Chem Phys. 1972;56(11):5499-5510.

11. Liao KS, Chen H, Awad S, et al. Determination of free-volume properties in polymers without orthopositronium components in positron annihilation lifetime spectroscopy. Macromolecules. 2011; 44(17):6818-6826.

12. Filipecki J, Kocela A, Korzekwa P, et al. Structural study of polymer hydrogel contact lenses by means of positron annihilation lifetime spectroscopy and UV-vis-NIR methods. J Mater Sci Mater Med. 2013;24(8):1837-1842.

13. Pathrick RA. Positron annihilation: A probe for nanoscale voids and free volume. Prog Polymer Sci. 1997;22(1):1-47.

14. Noda I. Two-dimensional infrared (2D IR) spectroscopy: Theory and applications. App/ Spectrosc. 1990;44(4):550-561.

15. Koenig JL. Spectroscopy of Polymers. $2^{\text {nd }}$ ed. New York, NY: Elsevier Science Inc.; 1999.

16. Ramanathan T, Fisher FT, Ruoff RS, Brinson LC. Amino-functionalized carbon nanotubes for binding to polymers and biological systems. Chem Mater. 2005;17(6):1290-1295.

17. Mandecki R, Filipecki J. Teleradiotherapy and brachytherapy [in Polish]. Prace Naukowe AJD w Częstochowie FIZYKA IX. 2014;9:95-116.

18. Andreo P, Burns DT, Hohlfeld K, et al. Absorbed Dose Determination in External Beam Radiotherapy: An International Code of Practice for Dosimetry based on Standards of Absorbed Dose to Water. Vienna, Austria: International Atomic Energy Agency (IAEA); 2006.

19. Filipecki J, Golis E, Reben M, Filipecka K, Kocela A, Wasylak J. Positron lifetime spectroscopy as a method to study of the defect degree materials with disordered structure. Optoelectron Adv Mat. 2013;7(11-12):1029-1031.

20. Reben M, Golis E, Filipecki J, et al. Voids in mixed-cation silicate glasses: Studies by positron annihilation lifetime and Fourier transform infrared spectroscopies. Spectrochim Acta A Mol Biomol Spectrosc. 2014;129:643-648.

21. Filipecki J, Sitarz M, Kocela A, et al. Studying functional properties of hydrogel and silicone-hydrogel contact lenses with PALS, MIR and Raman spectroscopy. Spectrochim Acta A Mol Biomol Spectrosc. 2014;131:686-690.

22. Kansy J. Microcomputer program for analysis of positron annihilation lifetime spectra. Nucl Instrum Methods Phys Res Section A. 1996;374(2):235-244.

23. Krause-Rehberg R, Leipner HS. Positron Annihilation in Semiconductors. Defect Studies. Berlin-Heidelberg-New York: SpringerVerlag; 1999.

24. Jean YC, David Van Horn J, Wei-Song H, Kuier-Rarn L. Perspective of positron annihilation spectroscopy in polymers. Macromolecules. 2013;46(18):7133-7145. 
25. Rosiak JM, Olejniczak J. Medical applications of radiation formed hydrogel. Radiat Phys Chem. 1993;42(4):903-906.

26. Tranoudis I, Efron N. Water properties of soft contact lens materials. Cont Lens Anterior Eye 2004;27:193-208.

27. Krysztofiak K, Szyczewski A. Study of dehydration and water states in new and worn soft contact lens materials. Optica Applicata. 2014;44(2):237-249.

28. Mullarney MP, Seery TAP, Weiss RA. Drug diffusion in hydrophobically modified $\mathrm{N}, \mathrm{N}$-dimethylacrylamide hydrogels. Polymer. 2006;47(11):3845-3855. 